\title{
Which is the best strategy for using diuretics in decompensated chronic heart failure?
}

\author{
Bonasia Vincenzo ${ }^{\#}$, Del Torre Martina ${ }^{\#}$ and De Carli Marco* \\ Second Unit of Internal Medicine, Department of Medicine, Azienda Sanitaria Universitaria Integrata di Udine, Udine, p.le S. Maria della Misericordia 15, 33100, \\ Udine, Italy \\ \#These authors equally contributed to the paper.
}

\begin{abstract}
Heart failure is a common clinical syndrome with symptoms and signs caused by cardiac dysfunction with inability of the heart to supply the metabolic demands of peripheral tissues with the required amount of blood and oxygen. HF is a chronic condition that may worsen acutely. This condition, known as decompensated heart failure, presents with symptoms and signs related to congestion. Although diuretics are drugs of first choice to control fluid retention, diuretic therapy is still empirical and no conclusive data are available on how these drugs should be managed in decompensated heart failure.
\end{abstract}

Here, we review the role of the different diuretics in decompensated heart failure and we illustrate the different strategies of diuretic therapy that have been proposed in literature.

Abbreviations: HF: heart failure; AHF: acute heart failure; ADHF: acute decompensated heart failure; LD: loop diuretics; AKI: acute kidney injury; CRS: cardiorenal syndrome; NCC: sodium-chloride cotransporter; MRA: Mineralocorticoid receptor antagonists.

\section{Introduction}

Heart failure (HF) is defined by The Task Force for the diagnosis and treatment of acute and chronic HF of the European Society of Cardiology (ESC), as a "structural and/or functional cardiac abnormality, resulting in a reduced cardiac output and/or elevated intracardiac pressures at rest or during stress" [1]. Clinical symptoms are breathlessness, ankle swelling and fatigue and other signs (such as elevated jugular venous pressure, pulmonary crackles and peripheral oedema) may accompany them [1]. Diagnosis can be made in subjects with symptoms of HF at rest or during exercise with objective evidence of systolic and/or diastolic cardiac dysfunction at rest. In uncertain cases, the favorable response to treatment confirms the diagnosis of HF [1,2]. HF is mostly a chronic condition characterized by episodic worsening of symptoms and signs that may require hospitalization or outpatients' visits. HF may also present acutely (AHF) within 24 hours, as acute pulmonary edema, or cardiogenic shock, or acute worsening of a chronic HF [3]. This last condition is properly a decompensation of HF (ADHF) with signs and symptoms of congestion and fluid retention due to the lack of those compensatory mechanisms that maintain the hemodynamic stability despite worsening of left ventricular function [4].

The prevalence and incidence increase progressively with age, with an overall prevalence estimated of $2.6 \%$ [5] and an incidence of 5-10 per 1,000 subjects per year [3]. HF is becoming more common due to better care and treatment of coronary artery disease, valvular disease and hypertension, and to the longer life expectancy in the general population [6]. HF mortality has declined over the time due to introduction of medications and devices that improve survival [1].
Despite improvements in the treatment, HF diagnosis is still associated with high hospitalization and mortality. In the United States in 2014, 900,000 hospital discharges were registered for HF [7]. The incidence of hospitalization for HF in patients over 55 years was 11.6 per 1,000 people per year and recurrent hospitalization for HF was 6.6 per 1,000 people per year [7]. Overall, median length of hospitalization has been estimated in 8 days with a range between 4 and 11 days, whereas the 30 -day HF readmission rate is 5.6\% [8]. Overall in-patient mortality rate has been recently evaluated at $9.6 \%$ [9], whereas the estimated survival is $72-75 \%$ at 1 year and $35-52 \%$ at 5 years [10].

\section{Diuretic therapy in HF}

Diuretics are a wide group of different drugs used in diverse therapeutic settings. In HF, they are used as first-line therapy to relieve symptoms and signs, and to reduce the episodes of decompensation, thus preventing hospitalization. They induce a rapid improvement of dyspnea and increase exercise tolerance, but evidence on their ability to prevent mortality is still controversial [11]. In the short term, they affect symptoms of fluid congestion, since they reduce the volume overload by increasing urinary flow and water excretion.

As shown in Table 1, most of diuretics act at different sites in the nephron by reducing sodium chloride reabsorption that in turn results

*Correspondence to: Marco De Carli, Second Unit of Internal Medicine, Department of Internal Medicine, Azienda Sanitaria Universitaria Integrata di Udine, Piazzale Santa Maria della Misericordia, 15, 33100 Udine, Italy, Tel: +39 0432 552607, +34 9814 2455, E-mail: decarli.marco@libero.it

Key words: heart failure, diuretics, loop diuretics, diuretic resistance, urinary sodium, bolus vs. infusion

Received: May 23, 2019; Accepted: June 18, 2019; Published: June 24, 2019 
in an increase of urinary sodium and water loss. Diuretics work on specific transporters that reabsorb sodium and chloride. With the exception of spironolactone and its analogue, all the transporters specifically inhibited by diuretics are on the luminal face of the tubule. Therefore, to reach their target, diuretics must diffuse or be secreted into the tubular fluid [12]. Among the different groups of drugs, those of interest in HF therapy are loop diuretics (LD), thiazides, potassiumsparing diuretics and carbonic anhydrase inhibitors.

$\mathrm{LD}$ are the inhibitors of the $\mathrm{Na}^{+} / \mathrm{K}^{+} / 2 \mathrm{Cl}^{-}$symport in the thick ascending limb of the loop of Henle, thus affecting both $\mathrm{Na}^{+}$and $\mathrm{Cl}^{-}$ reabsorption. These diuretics are the strongest diuretics because the loop of Henle is the region of the nephron that -being without aquaporinshas the capacity to reabsorb most of the sodium. Therefore, natriuresis induced by diuretics is accompanied by water loss. The amount of diuresis is directly related to the dose of drug delivered, since diuresis increases as the loop diuretic increases in dose [12].

Available LD are furosemide, torsemide, bumetanide and ethacrynic acid. They are highly protein-bound and they must be secreted into the lumen [13] to reach their site of action. Furosemide is the most used diuretic drug of this class. Fifty percent of furosemide is excreted unchanged as active drug into the lumen, whereas the other $50 \%$ is conjugated to glucuronic acid by the kidney. Thus, in renal insufficiency the plasma half-life of furosemide is prolonged since both urinary excretion and renal conjugation are decreased [14]. Absorption of furosemide is erratic ranging from $10 \%$ to $100 \%$ both from patient to patient, as well as in the same patient (Table 1). In patients with congestive HF, the oral absorption of furosemide and of the other LD can be slowed by the congestion of the intestinal walls, hence the drug may not reach the threshold concentration to induce diuresis $[14,15]$. Absorption of bumetanide and torsemide is quite complete. These two drugs have a longer duration effect but are more expensive and not available in many countries [16]. The plasma halflives of LD range from 1 hour (bumetanide) to 3-4 hours (torsemide), with an intermediate half-life for furosemide (Table 1). Therefore, during therapy, there is a considerable time in which the drug does not reach adequate concentration at the site of action with the possible reabsorption of sodium that can override the natriuresis induced by LD [17]. Possible side effects related to LD are represented by hyponatremia, hypokalemia, hypocalcaemia, hypomagnesaemia [18] and ototoxicity (Table 2) [12]. The latter is dose dependent and it is due to the action of LD on a chloride channel of the inner ear, almost identical to the symport present in the loop of Henle [12].

\section{Loop diuretics: not the only ones. Thiazide or thiazide- like diuretics}

There are other classes of diuretics that can be useful in the management of HF, especially in diuretic resistance, a problem that will be dealt with later.

Thiazide diuretics encompass a large class of agents that block the sodium-chloride co-transporter (NCC) in the distal convoluted tubule (Table 1) [19], thus exhibiting a synergistic action with the LD, which cause sodium avidity in the distal tubule. The different molecules (hydrochlorothiazide, chlortalidone, chlorothiazide and metolazone) have a similar blocking effect on NCC, but they differ in terms of halflives and off-target effect (Table 1) [20]. In contrast with LD, metolazone and chlortalidone have a slow gastrointestinal absorption and a longer half-life, while chlorothiazide has a shorter half-life, differences that should be remembered when co-administered with LD. It is known that the natriuresis induced by these agents is lower (maximum 30-40\%) [19] compared to LD but the rationale for their use in HF is based on the finding of increased distal nephron sodium avidity in the case of loop diuretic administration [21]. Furthermore, there is evidence that these drugs are effective even in patients with glomerular filtration less than $30 \mathrm{ml} / \mathrm{min}$ [22]. However, they should be used with caution, remembering that they are more often associated with hypokalemia and hyponatremia [23]. Therefore, they should be used as a secondline agent in a stepped pharmacologic algorythm, in case of congestion "resistant" to high doses of LD, as recommended by the Heart Failure Society of America [24].

\section{Mineralocorticoid receptor antagonists (MRA)}

The mineralocorticoid blockers, spironolactone and eplerenone, act within cells and do not require secretion into the tubule lumen.

Table 1. Pharmacology of diuretics

\begin{tabular}{|c|c|c|c|c|}
\hline & Acetazolamide & Loop diuretics & Thiazide-like diuretics & MRA \\
\hline Site of action & Proximal nephron & Ascending loop of Henle & Early distal convoluted tubule & Late distal tubule \\
\hline $\begin{array}{l}\text { Starting dose/usual } \\
\text { chronic dose (mg) }\end{array}$ & $\begin{array}{l}\text { Oral: } 250-375 \\
\text { Intravenous: } 500\end{array}$ & $\begin{array}{l}\text { Furosemide: } 20-40 / 40-240 \\
\text { Torsemide: } 5-10 / 10-20\end{array}$ & $\begin{array}{c}\text { HCTZ: } 25 / 12.5-100 \\
\text { Metolazone: } 2.5 / 2.5-10 \\
\text { Chlorthalidone: } 25 / 25-200 \\
\text { Chlorothiazide: } 500-1000 \\
\text { (IV formulation available) }\end{array}$ & $\begin{array}{l}\text { Spironolactone: } 25 / 25-50 \\
\text { Eplerenone: } 25 / 25-50 \\
\text { Potassium canrenoate: } \\
25-200 / \text { not for } \\
\text { chronic use }\end{array}$ \\
\hline Maximum dose (mg) & $\begin{array}{l}\text { Oral: } 5003 \mathrm{x} / \text { day } \\
\text { Intravenous: } 5003 \mathrm{x} / \text { day }\end{array}$ & $\begin{array}{c}\text { Furosemide: } 400-600 \\
\text { Torsemide: } 200-300\end{array}$ & $\begin{array}{c}\text { HCTZ: } 200 \\
\text { Metolazone: } 20 \\
\text { Chlorthalidone: } 100 \\
\text { Chlorothiazide: } 1000\end{array}$ & $\begin{array}{l}50-100 \text { (doses up to } 400 \\
\text { are used in hepatology) }\end{array}$ \\
\hline Half-life & $2.4-5.4 \mathrm{~h}$ & $\begin{array}{l}\text { Furosemide: } 1.5-3.0 \mathrm{~h} \\
\text { Torsemide: } 3-6 \mathrm{~h}\end{array}$ & $\begin{array}{c}\text { HCTZ: } 6-15 \mathrm{~h} \\
\text { Metolazone: } 6-20 \mathrm{~h} \\
\text { Chlorthalidone: } 45-60 \mathrm{~h}\end{array}$ & $\begin{array}{l}\text { Canrenone: } 16.5 \mathrm{~h} \\
\text { Eplerenone: } 3-6 \mathrm{~h}\end{array}$ \\
\hline Oral bioavailability & $\begin{array}{c}\text { Absorption is dose-dependent, } \\
\text { dose }>10 \mathrm{mg} / \mathrm{kg} \text { exhibit } \\
\text { variable uptake }\end{array}$ & $\begin{array}{l}\text { Furosemide: } 10-100 \% \\
\text { Torsemide: } 80-100 \%\end{array}$ & $\begin{array}{c}\text { HCTZ: } 65-75 \% \\
\text { Metolazone: } 60-65 \% \mathrm{f} \\
\text { Chlorthalidone: unknown } \\
\text { Chlorothiazide: } 9-56 \%\end{array}$ & $\begin{array}{l}\text { Spironolactone: } \sim 90 \% \\
\text { Eplerenone: } 69 \%\end{array}$ \\
\hline Potency (FENa\%) & $4,00 \%$ & $20-25 \%$ & $5-8 \%$ & $2,00 \%$ \\
\hline
\end{tabular}

$\mathrm{FENa}=$ fractional excretion of sodium; $\mathrm{HCTZ}=$ hydrochlorothiazide; $\mathrm{MRA}=$ mineralocorticoid receptor antagonists.

Adapted from "The use of diuretics in heart failure with congestion - a position statement from the Heart Failure Association of the European Society of Cardiology". Eur J Heart Fail. $2019 ; 21: 137-155$ 
They modulate the expression of sodium and potassium channels in the distal nephron, induce poor natriuresis but they antagonize the adverse effects of hyperaldosteronism, particularly cardiac fibrosis. A remarkable reduction in mortality, risk of hospitalization and symptoms with their use were also demonstrated, as reported for spironolactone in the RALES study [25] and in the EPHESUS trial for the eplerenone [26]. For these reasons, these drugs have a class I recommendation as a disease modifying therapeutic agent in symptomatic chronic HF with ejection fraction below 35\%. In a more recent trial (ATHENA-HF) [27], spironolactone did not improve the primary end point of decongestion or secondary end points, including amelioration in symptoms and congestion. Potassium concentration in plasma was not affected however, suggesting incomplete mineralocorticoid receptor blockade [28]. Finally, MRA might be useful in offsetting the hypokalemic effect of potassium-wasting loop and thiazide diuretics.

\section{Acetazolamide}

The last group of diuretics of some interest in the therapy of HF is carbonic anhydrase inhibitor: acetazolamide is the only one with relevant diuretic effects. It acts on the proximal tubule [12]. In HF, it has a limited use because of the transient effect on diuresis and of the risk of metabolic acidosis with its prolonged administration. It may be useful to correct metabolic alkalosis that can happen with vigorous therapy with thiazide or loop diuretics [19]. A multicenter, randomized, double-blind trial of the diuretic effects of Acetazolamide in Decompensated heart failure with Volume OveRload (ADVOR) will investigate if combination therapy with acetazolamide improves loop diuretic response to increase diuresis in decompensated heart failure patients [29]. Observational studies have only assessed the role of intravenous acetazolamide, and no data are available supporting the role of oral acetazolamide.

\section{Primum non nocere: renal failure and adverse events}

The most common concern of the clinician in the management of diuretic therapy is renal failure, as this may precede but also complicate the treatment of HF. There is a highly interdependent relationship between the kidney and the heart, and an acute or chronic dysfunction in one organ may induce acute or chronic dysfunction in the other, namely the cardiorenal syndrome (CRS) [30]. LD have multiple effects on neurohormonal activation and renal and systemic hemodynamics that can predispose to kidney injury. Worsening kidney function in

Table 2. Common side effect of diuretics

Loop diuretics

Mineralcorticoid receptor antagonist (MRA)

Thiazide or thiazide-like diuretics
AHF (type 1 CRS) is associated with higher re-hospitalization rates and mortality [31]. Determining the significance of fluctuations in kidney function that meet the criteria for acute kidney injury (AKI) in the context of CRS represents a core challenge in its definition, particularly in the setting of AHF. In AHF, decongestive therapies may complicate the assessment of biomarkers of renal function (especially for serum creatinine and urine output) [19]. It is thus essential to distinguish a true AKI, with tubular lesion and pseudo-AKI, to prevent sub-optimal administration of appropriate targeted therapies such as decongestion and inhibition of the renin-angiotensin-aldosterone system (RAAS) in CRS [32]. Several studies have assessed the clinical benefit of different dosing protocols for LD in AHF and their effect on kidney function. In the DOSE-AHF Trial [33], there was a trend in favor of the high-dose strategy compared with the standard dose in symptom improvement $(P=0.06)$, without a significant difference change in renal function $(P=0.21)$. In an ancillary study of ROSE-AHF [34], investigators measured biomarkers of kidney injury in individuals taking highdose furosemide. In this analysis, kidney tubular injury detected by biomarkers did not appear to have an association with worsening renal function in the context of aggressive diuresis of individuals with AHF. These studies in AHF would suggest that LD per se may not contribute to a biomarker-associated renal injury, and a decrease in the eGFR may be a surrogate for severity of cardiac disease. In fact, post hoc analyses of large trials suggest that those who experience a moderate increase in creatinine (worsening kidney function) may actually have a better prognosis than those who do not [35]. Furthermore, without guidance from assessment of blood volume, rate of plasma refill, or measures of acute tubular injury, it is clear that the use of diuretics in HF is empirical without a proven strategy associated with favorable outcomes from either observational studies or randomized trials. This raises hopes for future trials guided by these parameters to improve outcomes compared with usual care [30].

The adverse effects of diuretic therapy are related to the site and to the mechanism of action. Common side effects are listed in Table 2 [35].

\section{Diuretic resistance}

Diuretic resistance is defined as a failure to achieve an appropriate state of decongestion despite a full dose of diuretics [36]. Diuretic resistance is a common problem, it is reported in up to a third of HF patients hospitalized with worsening symptoms and it is associated with poor prognosis. Removal of excessive fluid is usually achieved by

Hypersensitivity reactions

Extracellular fluid volume depletion

Hypokalemic alkalosis

Hypomagnesemia

Ototoxicity

Hypersensitivity reactions

Hyponatremia

Hypokalemic alkalosis

Hyperglycemia / Diabetes

Hyperuricemia / gout

Hypomagnesemia

Hypokalemia and prerenal azotemia, when combined with loop diuretics

Hypersensitivity reactions

Hyperkalemia

Metabolic acidosis

Azotemia

Azotemia, vaginal bleeding (spironolactone) 
a combination of salt restriction and $\mathrm{LD}$, but in some cases congestion persists despite adequate diuretic therapy. The exact prevalence of diuretic resistance in the HF population is unknown due to the heterogeneity of the population studied, the different treatment regimens, as well as to the different definitions used in various clinical trials [37]. HF shifts the dose-response curve for LD downward and to the right. Thus, a higher starting dose of LD is needed in order to achieve the same level of sodium excretion [38]. The magnitude of natriuresis following a defined dose of diuretics declines over time, even in normal subjects. This is the so-called "braking phenomenon" and it is the result of both hemodynamic changes at the glomerulus as well as adaptive changes in the distal nephron [39]. Establishing the cause of diuretic resistance is important because it directly gives the options for intervention. For example, diuretic resistance is often treated effectively by combining a LD with another type of diuretic [40]. The different mechanisms which explain the diuretic resistance will be discussed below.

LD activate the renin-angiotensin-aldosterone system and the sympathetic nervous system, both of which tend to reduce renal blood flow and increase reabsorption of sodium in the proximal and distal tubule. Absolute or relative decreases in intravascular volume with ongoing diuretic therapy lead to a decrease in the amount of sodium filtered by the glomerulus and an increase in the amount of sodium reabsorbed [17]. Chronic LD therapy also leads to structural changes in the kidney itself, particularly hypertrophy of the epithelial cells in the distal tubules, which increase distal reabsorption of sodium and reduce sodium excretion and diuresis [41]. The combined effects of HF, frequent concomitant renal insufficiency, and physiological braking all contribute to the clinical phenomenon of diuretic resistance, in which patient have persistent evidence of volume overload but are progressively resistant to the effects of LD [42]. Another mechanism which could be involved is the decreased drug bioavailability, meaning that increased peripheral and bowel wall edema lead to reduced absorption of the diuretic, in particular with oral furosemide $[43,44]$. Other causes of drug resistance could be drug interactions: non-steroidal anti-inflammatory drugs, steroids or pioglitazone can reduce the effects of diuretics. To conclude, pseudo-resistance may exist, meaning poor compliance of the patient can be misinterpreted as diuretic resistance. A good clinical history can help in identifying this.

A response reduction to diuretic therapy is a common problem in patients with HF. While many studies tried to give an exact clinical definition of diuretic resistance, others tried to find a solution to solve the clinical problem. A possible way of overcoming diuretic resistance is to use infusion therapy to avoid the limitations of oral bioavailability. For patients refractory to escalating doses of intravenous diuretics, options include use of continuous infusion rather than intermittent boluses. Another approach is to administer two classes of diuretics together, a LD combined with a thiazide-like diuretic, thus performing a sequential nephron blockade [45]. In fact, the longer half-life of thiazide diuretics helps to counteract the rebound post-diuretic effect [46]. Moreover, thiazide-type diuretics inhibit sodium reabsorption in the distal nephron and primarily are useful for patients who have distal nephron hypertrophy and hyperfunctioning due to chronic treatment with LD [47]. This approach requires very close monitoring as it can lead to electrolyte disturbance, hypotension, dehydration, and worsening renal function. Restricting excessive dietary sodium and fluid intake can also help reduce diuretic resistance by reducing sodium and fluid load arriving at the nephron level. This strategy can be unpleasant for patients and it is unusual for a patient to be able to tolerate less than 1.5 liters of daily fluid intake for more than a few days [48].

\section{How to evaluate diuretic response}

The mostly used parameters to evaluate response to diuretic therapy are usually body weight and daily diuresis. Even though it seems easy to gather them, this does not always correspond to reality. As a matter of fact, daily weight is a measure which must be taken in a precise way in order to be helpful, meaning weighing the patient with the same device, same clothes, etc.; moreover, daily weight does not always reflect changes in body fluid volumes and it can be influenced by other factors. Post-discharge changes in body weight only predicted re-hospitalization and were unrelated to mortality in one study [49], highlighting the limits of examining body weight alone. Other Authors found that diuretic dose did not predict weight loss [50,51].

As a result, considerable discrepancy between fluid balance and weight loss is a common issue in patients treated for acute decompensated HF. Awareness of the limits inherent to these commonly used metrics and efforts to develop more reliable measures of diuresis are critical for both patient care and research in acute decompensated HF [52].

A new parameter, which is gaining more and more importance, is urinary sodium. Diuretic response may be evaluated using urinary volume output and post-diuretic (spot) urinary sodium content. To allow for standardization and reliable results, patients presenting with congestion need to empty their bladder before the administration of diuretics. The degree of bladder emptying could potentially be checked using a bladder scan. Afterwards, determination of urinary spot sodium content allows the clinician to interpret diuretic response, thereby generating the opportunity to intervene if sodium content is low. In the event of congestion with volume overload, a spot urine sodium content of $<50-70 \mathrm{mEq} / \mathrm{L}$ after $2 \mathrm{~h}$, and/or an hourly urine output $<100-150$ $\mathrm{mL}$ during the first $6 \mathrm{~h}$, generally identifies a patient with an insufficient diuretic response [53-55].

A position statement from the Heart Failure Association of the European Society of Cardiology proposed a flowchart on the use of diuretics in $\mathrm{HF}$ and how to evaluate the response to diuretic therapy using these measures that we have summarized in Figure $1[20,56]$.

Moreover, a study conducted by Jan Biegus et al enrolled 111 AHF patients to study the association of serial measurements of spot urinary sodium during the first $48 \mathrm{~h}$ of AHF treatment with the indices of decongestion, renal function, and prognosis. They concluded that low spot urinary sodium and lack to increase urinary sodium in response to intravenous diuretics are associated with poor diuretic response, markers of tubular injury and high risk of 1-year mortality [57].

\section{Is there a safer way to use diuretics: bolus versus infusion?}

We have already mentioned that high doses of LD may have detrimental effects, including activation of renin-angiotensin and sympathetic nervous systems, electrolyte imbalance, and worsening of renal function [58]. Moreover, observational studies have demonstrated associations between high doses of diuretics and adverse clinical outcomes, such as renal failure, progression of HF, and death $[50,59,60]$. In the Studies of Left Ventricular Function Trial, the use of a diuretic was associated with a $37 \%$ increase in the risk of arrhythmic death after controlling for multiple other measures of disease severity [60]. Several other studies identified an association between higher doses of diuretics in patients and adverse outcomes in patients with ADHF [61,62] and advanced HF outpatients[63-65] and inpatients [50]. Analysis of the data from the Evaluation Study of Congestive Heart Failure and 


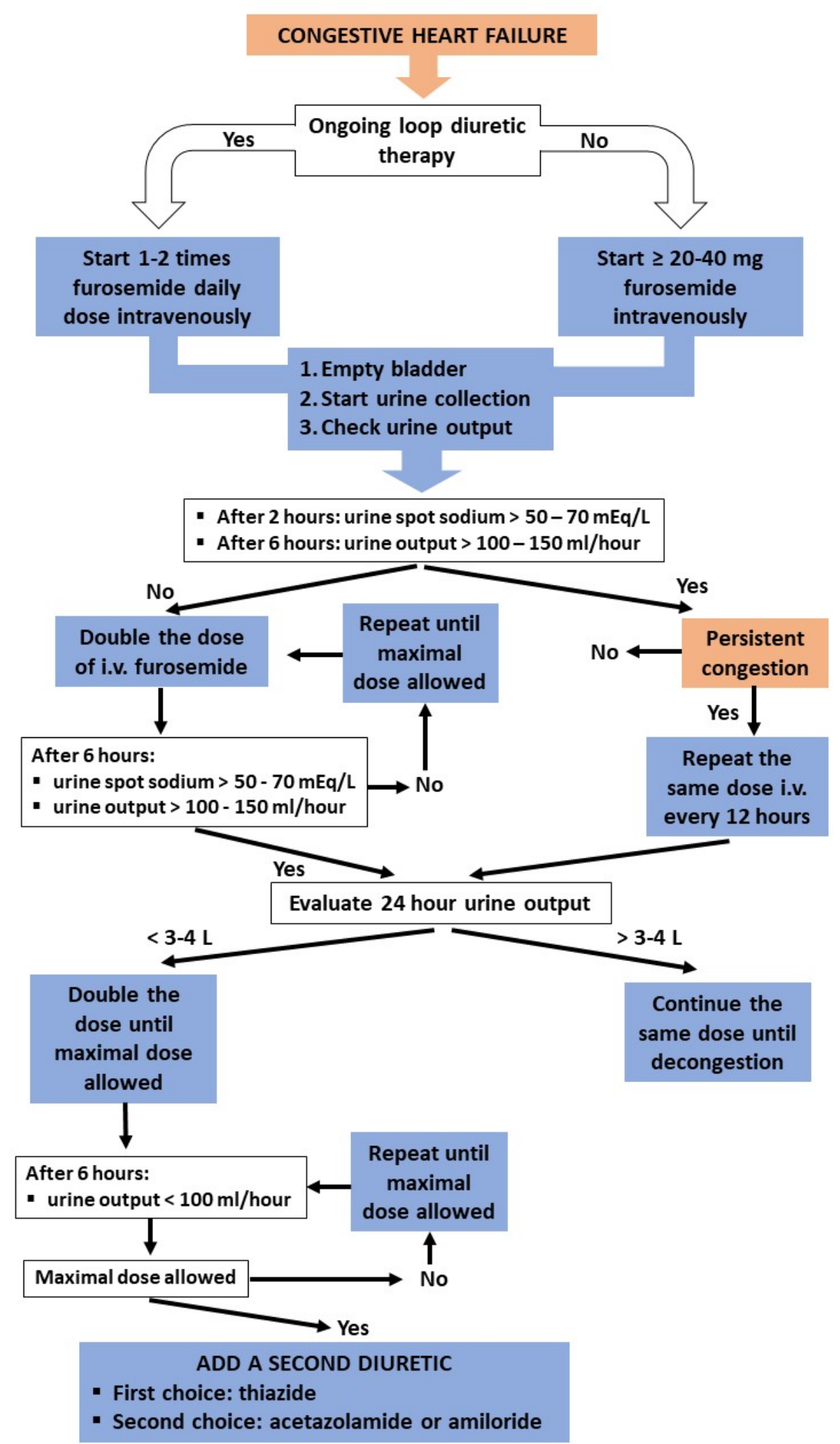

Figure 1. Proposed algorythm on the use of diuretics in heart failure and on the evaluation of response to diuretic therapy (adapted from "The use of diuretics in heart failure with congestion - a position paper from the Heart Failure Association of the European Society of Cardiology". Eur J Heart Fail. 2019;21:137-155) 
Pulmonary Artery Catheterization Effectiveness Study demonstrated a nearly linear relationship between LD dose and mortality over 6 months of follow-up in patients hospitalized with advanced HF [50]. All such data may be highly confounded according by the clinical indication (i.e., patients who receive higher doses of diuretics usually have greater disease severity compared with patients who can be successfully treated with lower doses of diuretics). The concerns about safety and efficacy suggest the need to identify the better strategies for using LD in ADHF. In addition, ongoing uncertainty exists about the optimal route of administration of i.v. LD (bolus or continuous infusion). From the pharmacokinetics and pharmacodynamics points of view, there are potential benefits of continuous infusion when compared with intermittent bolus dosing. Bolus diuretic dosing may be associated with a higher rate of diuretic resistance due to prolonged periods of subtherapeutic drug levels in the kidney. For example, giving an i.v. bolus of furosemide twice-daily results in a 4- to 6-hour period of diuretic effect, followed by a 6- to 8-hour period of subtherapeutic diuretic concentration during which sodium reabsorption in the kidney may rebound, especially in the context of inadequate dietary sodium restriction [17]. Continuous infusion results in a more constant delivery of diuretic to the tubule, potentially reducing this phenomenon. Additionally, continuous infusion is associated with lower peak plasma concentrations, which may result in a lower incidence of side effects such as ototoxicity. In light of these uncertainties, the National Heart, Lung, and Blood Institute Heart Failure Clinical Research Network conducted the Diuretic Optimization Strategies Evaluation (DOSE) trial, a clinical trial of various diuretic strategies for patients with acute decompensated HF. In a prospective, double-blind, randomized trial, they assigned 308 patients with acute decompensated HF to receive furosemide administered intravenously by means of either a bolus every 12 hours or continuous infusion and at either a low dose (equivalent to the patient's previous oral dose) or a high dose (2.5 times the previous oral dose). Among patients with acute decompensated HF, there were no significant differences in patients' global assessment of symptoms or in the change in renal function when diuretic therapy was administered by bolus as compared with continuous infusion or at a high dose as compared with a low dose [33]. After this, several trials tried to evaluate and compare the two ways to administer diuretics in acute decompensated HF. A recent meta-analysis from the Cochrane Collaboration comprehensively evaluated the available literature [66] and identified studies including 254 patients who met rigorous analytic standards [67-73]. In general, continuous infusion was associated with greater urine output (Table 3), shorter length of hospital stay, less impairment of renal function, and lower mortality when compared with intermittent bolus dosing. Notably, however, almost all the conclusions of this meta-analysis were driven by a single study by Licata et al, which was substantially confounded by the use of hypertonic saline infusion in the continuous infusion group. In their conclusions, the Authors highlighted the poor quality of the available data and the need for methodologically conducted and adequately powered randomized trials [66,74]. We could mention many other examples. For instance, Palazzuoli et al found that, in the setting of ADHF, continuous infusion of LD resulted in greater reductions in BNP from admission to discharge. However, this appeared to occur as the consequence of worsened renal filtration function, use of additional treatment, and higher rates of re-hospitalization or death at six months [75]. According to $\mathrm{Ng}$ et al, there was no difference between continuous infusion and bolus of furosemide for all-cause mortality, length of hospital stay and electrolyte disturbance, but continuous infusion was superior to bolus administration with regard to diuretic effect and reduction in brain natriuretic peptide [76]. To cite another trial, Kuriyama found no differences in hypokalemia, hyponatremia, increased serum creatinine level, and hypotension between the two regimens. Continuous infusion of furosemide compared to intermittent administration-, is associated with a greater body weight reduction and potential increase in 24-h urine output. The limited available evidence suggests no difference in adverse events between both strategies [77].

Taking into account all the aforementioned data, our conclusion is that to date there is no evidence of relevant differences between administering LD in bolus versus infusion in terms of effectiveness and safety. We suggest a case-by-case consideration, and maybe opt for bolus in younger and active patients, in order to allow them not to remain connected to their drip all day long, and prefer, instead, continuous infusion in patients who take high doses of oral diuretics at home or those with predisposing factors for diuretic resistance.

\section{Acknowledgments}

We thank Dr. Caterina Degano Massimo for her valuable support in proof reading and editing of this work.

\section{References}

1. Ponikowski P, Voors AA, Anker SD, Bueno H, Cleland JG, et al. (2016) ESC Guidelines for the diagnosis and treatment of acute and chronic heart failure: The task force for the diagnosis and treatment of acute and chronic heart failure of the European society of cardiology (ESC). Developed with the special contribution of the heart failure association (HFA) of the ESC. Eur J Heart Fail 18: 891-975. [Crossref]

2. Tanai E, Frantz S (2015) Pathophysiology of heart failure. Compr Physiol 6: 187-214. [Crossref]

3. Mosterd A, Hoes AW (2007) Clinical epidemiology of heart failure. Heart 93: 1137 1146. [Crossref]

Table 3. Randomized trials of bolus versus continuous infusion of diuretics in heart failure

\begin{tabular}{|c|c|c|c|c|c|}
\hline Study & Number of patients & Design of the study & Duration & End points & Results \\
\hline Aaser et al [68] & 8 & $\begin{array}{l}\text { Randomized, cross-over, } \\
\text { unblinded }\end{array}$ & 24 hours & Urine output & Bolus better \\
\hline Dormans et al [70] & 20 & $\begin{array}{c}\text { Randomized, cross-over, } \\
\text { unblinded }\end{array}$ & 24 hours & Urine output & Infusion better \\
\hline Kramer et al [71] & 8 & $\begin{array}{c}\text { Randomized, cross-over, } \\
\text { unblinded }\end{array}$ & 24 hours & Urine output & No difference \\
\hline Lahav et al [72] & 9 & $\begin{array}{c}\text { Randomized, cross-over, } \\
\text { unblinded }\end{array}$ & 48 hours & Urine output & Infusion better (trend) \\
\hline Licata et al [74] & 107 & Randomized, single-blind & 6-12 days & $\begin{array}{l}\text { Urine output at } 24 \text { hours } \\
\text { and Mortality }\end{array}$ & $\begin{array}{l}\text { Infusion better on all end } \\
\text { points }\end{array}$ \\
\hline Pivac et al [69] & 20 & $\begin{array}{l}\text { Randomized, single-blind, } \\
\text { cross-over }\end{array}$ & 24 hours & Urine output & Infusion better \\
\hline Schuller et al [73] & 33 & Randomized, unblinded & 72 hours & Mortality & No difference \\
\hline
\end{tabular}


4. Kurmani S, Squire I (2017) Acute heart failure: Definition, classification and epidemiology. Curr Heart Fail Rep 14: 385-92.

5. Redfield MM, Jacobsen SJ, Burnett JC Jr, Mahoney DW, Bailey KR, et al. (2003) Burden of systolic and diastolic ventricular dysfunction in the community: appreciating the scope of the heart failure epidemic. JAMA 289: 194-202. [Crossref]

6. Heidenreich PA, Albert NM, Allen LA, Bluemke DA, Butler J, et al. (2013) Forecasting the impact of heart failure in the United States: a policy statement from the American heart association. Circ Heart Fail 6: 606-619.

7. Benjamin EJ, Virani SS, Callaway CW, Chamberlain AM, Chang AR, et al. (2018) Heart disease and stroke statistics-2018 Update: A report from the American heart association. Circulation 137: e67-67e492. [Crossref]

8. Khan H, Greene SJ, Fonarow GC, Kalogeropoulos AP, Ambrosy AP,et al. (2015) Length of hospital stay and 30-day readmission following heart failure hospitalization: insights from the EVEREST trial. Eur J Heart Fail. 17: 1022-1031.

9. Donkor A, Cleland J, McDonagh T, Hardman S (2016) National heart failure audit 11.07.2016.

10. Orso F, Fabbri G, Maggioni AP (2017) Epidemiology of heart failure. Handb Exp Pharmacol 243: 15-33. [Crossref]

11. Faris RF, Flather M, Purcell H, Poole-Wilson PA, Coats AJ (2012) Diuretics for heart failure. Cochrane Database Syst Rev 15: CD003838.

12. Wile D (2012) Diuretics: a review. Ann Clin Biochem 49: 419-431. [Crossref]

13. Sica DA, Gehr TWB, Frishman WH (2017) Use of diuretics in the treatment of heart failure in older adults. Heart Fail Clin 13: 503-512. [Crossref]

14. Brater DC (1998) Diuretic therapy. N Engl J Med 339: 387-395. [Crossref]

15. Vasko MR, Cartwright DB, Knochel JP, Nixon JV, Brater DC (1985) Furosemide absorption altered in decompensated congestive heart failure. Ann Intern Med 102: 314-318. [Crossref]

16. Islam MS (2018) The art and science of using diuretics in the treatment of heart failure in diverse clinical settings. Adv Exp Med Biol 1067: 47-65. [Crossref]

17. Wilcox CS, Mitch WE, Kelly RA, Skorecki K, Meyer TW, et al. (1983) Response of the kidney to furosemide. I. Effects of salt intake and renal compensation. J Lab Clin Med 102: 450-458. [Crossref]

18. Bronner F (1989) Renal calcium transport: mechanisms and regulation--an overview. Am J Physiol 257: F707-F711. [Crossref]

19. Knauf H, Mutschler E (1991) Pharmacodynamic and kinetic considerations on diuretics as a basis for differential therapy. Klin Wochenschr 69: 239-250. [Crossref]

20. Mullens W, Damman K, Harjola VP, Mebazaa A, Brunner-La Rocca HP, et al. (2019) The use of diuretics in heart failure with congestion - a position paper from the heart failure association of the European society of cardiology. Eur J Heart Fail 21: 137-155.

21. Rao VS, Planavsky N, Hanberg JS, Ahmad T, Brisco-Bacik MA, et al. (2017) Compensatory distal reabsorption drives diuretic resistance in human heart failure. $J$ Am Soc Nephrol 28: 3414-3424. [Crossref]

22. Agarwal R, Sinha AD (2012) Thiazide diuretics in advanced chronic kidney disease. $J$ Am Soc Hypertens 6: 299-308.

23. Brisco-Bacik MA, Ter Maaten JM, Houser SR, Vedage NA, Rao V, et al. (2018) Outcomes associated with a strategy of adjuvant metolazone or high-dose loop diuretics in acute decompensated heart failure: A propensity analysis. $J$ Am Heart Assoc 7: e009149.

24. Heart failure society of America, Lindenfeld J, Albert NM, Boehmer JP, Collins SP, et al. (2010) HFSA 2010 comprehensive heart failure practice guideline. J Card Fail 16: e1-e194.

25. Pitt B, Zannad F, Remme WJ, Cody R, Castaigne A, et al. (1999) The effect of spironolactone on morbidity and mortality in patients with severe heart failure. Randomized aldactone evaluation study investigators. N Engl J Med 341: 709-717. [Crossref]

26. Pitt B, Remme W, Zannad F, Neaton J, Martinez F, et al. (2003) Eplerenone, a selective aldosterone blocker, in patients with left ventricular dysfunction after myocardial infarction. $N$ Engl J Med 348: 1309-1321. [Crossref]

27. Butler J, Anstrom KJ, Felker GM, Givertz MM, Kalogeropoulos AP, et al. (2017) Efficacy and safety of spironolactone in acute heart failure: the ATHENA-HF randomized clinical trial. JAMA Cardiol 2: 950-958.

28. Ellison DH, Felker GM (2017) Diuretic treatment in heart failure. N Engl J Med 377 : 1964-1975. [Crossref]
29. Mullens W, Verbrugge FH, Nijst P, Martens P, Tartaglia K, et al. (2018) Rationale and design of the ADVOR (Acetazolamide in decompensated heart failure with volume overload) trial. Eur J Heart Fail. 20: 1591-600.

30. Rangaswami J (2019) Cardiorenal syndrome: Classification, pathophysiology, diagnosis, and treatment strategies. Circulation 139: e840-78.

31. Ronco C, Cicoira M, McCullough PA (2012) Cardiorenal syndrome type 1 : pathophysiological crosstalk leading to combined heart and kidney dysfunction in the setting of acutely decompensated heart failure. J Am Coll Cardiol 60: 1031-1042.

32. Damman K, Tang WH, Testani JM, McMurray JJ (2014) Terminology and definition of changes renal function in heart failure. Eur Heart J 35: 3413-3416. [Crossref]

33. Felker GM, Lee KL, Bull DA, Redfield MM, Stevenson LW, et al. (2011) Diuretic strategies in patients with acute decompensated heart failure. $N$ Engl J Med 364: $797-$ 805. [Crossref]

34. Chen HH, Anstrom KJ, Givertz MM, Stevenson LW, Semigran MJ, et al. (2013) Lowdose dopamine or low-dose nesiritide in acute heart failure with renal dysfunction: the ROSE acute heart failure randomized trial. JAMA 310: 2533-2543. [Crossref]

35. Ellison DH (2019) Clinical pharmacology in diuretic use. Clin J Am Soc Nephrol. [Crossref]

36. Hoorn EJ, Ellison DH (2017) Diuretic resistance. Am J Kidney Dis 69: 136-142. [Crossref]

37. Casu G, Merella P (2015) Diuretic therapy in heart failure - Current approaches. Eur Cardiol 10: 42-47. [Crossref]

38. Ellison DH (2001) Diuretic therapy and resistance in congestive heart failure. Cardiology 96: 132-143. [Crossref]

39. Kaissling B, Stanton BA (1988) Adaptation of distal tubule and collecting duct to increased sodium delivery. I. Ultrastructure. Am J Physiol 255: F1256-F12568. [Crossref]

40. Ellison DH (1991) The physiologic basis of diuretic synergism: its role in treating diuretic resistance. Ann Intern Med 114: 886-894.

41. Wilcox CS, Mitch WE, Kelly RA, Skorecki K, Meyer TW, et al. (1983) Response of the kidney to furosemide. I. Effects of salt intake and renal compensation. $J$ Lab Clin Med 102: 450-458. [Crossref]

42. Kaissling B, Bachmann S, Kriz W (1985) Structural adaptation of the distal convoluted tubule to prolonged furosemide treatment. Am J Physiol 248: F374-F381.

43. Stevenson LW, Nohria A, Mielniczuk L (2005) Torrent or torment from the tubules? Challenge of the cardiorenal connections. J Am Coll Cardiol 45: 2004-2007. [Crossref]

44. Brater DC, Day B, Burdette A, Anderson S (1984) Bumetanide and furosemide in heart failure. Kidney Int 26: 183-189. [Crossref]

45. Vasko MR, Cartwright DB, Knochel JP, Nixon JV, Brater DC (1985) Furosemide absorption altered in decompensated congestive heart failure. Ann Intern Med 102 314-318.

46. Knauf H, Mutschler E (1997) Sequential nephron blockade breaks resistance to diuretics in edematous states. J Cardiovasc Pharmacol 3: 367-372.

47. Schrier RW (2006) Role of diminished renal function in cardiovascular mortality: marker or pathogenetic factor? J Am Coll Cardiol 47: 1-8. [Crossref]

48. Verbrugge FH, Grieten L, Mullens W (2014) Management of the cardiorenal syndrome in decompensated heart failure. Cardiorenal Med 4: 176-188.

49. Vazir A, Cowie MR (2016) Decongestion: Diuretics and other therapies for hospitalized heart failure. Indian Heart Journal 68: S61-S68.

50. Blair JE, Khan S, Konstam MA, Swedberg K, Zannad F, et al. (2009) Weight changes after hospitalization for worsening heart failure and subsequent re-hospitalization and mortality in the EVEREST trial. Eur Heart J 30: 1666-1673. [Crossref]

51. Hasselblad V, Gattis Stough W, Shah MR, Lokhnygina Y, O'Connor CM, et al. (2007) Relation between dose of loop diuretics and outcomes in a heart failure population: results of the ESCAPE trial. Eur J Heart Fail 9: 1064-1069.

52. Kociol RD, McNulty SE, Hernandez AF, Lee KL, Redfield MM, et al. (2013) Markers of decongestion, dyspnea relief, and clinical outcomes among patients hospitalized with acute heart failure. Circ Heart Fail 6: 240-245.

53. Testani JM, Brisco MA, Kociol RD, Jacoby D, Bellumkonda L, et al. (2015) Substantia discrepancy between fluid and weight loss during acute decompensated heart failure treatment: Important lessons for research and clinical care. Am J Med 128: 776-783. 
54. Singh D, Shrestha K, Testani JM, Verbrugge FH, Dupont M, et al. (2014) Insufficient natriuretic response to continuous intravenous furosemide is associated with poor longterm outcomes in acute decompensated heart failure. J Card Fail 20: 392-399. [Crossref]

55. Testani JM, Hanberg JS, Cheng S, Rao V, Onyebeke C, et al. (2016) Rapid and highly accurate prediction of poor loop diuretic natriuretic response in patients with heart failure. Circ Heart Fail 9: e002370.

56. Buckley LF, Carter DM, Matta L, Cheng JW, Stevens C, et al. (2016) Intravenous diuretic therapy for the management of heart failure and volume overload in a multidisciplinary outpatient unit. JACC Heart Fail 4: 1-8.

57. Mullens W, Damman K, Harjola VP, Mebazaa A, Brunner-La Rocca HP, et al. (2019) The use of diuretics in heart failure with congestion - a position statement from the heart failure association of the European society of cardiology. Eur J Heart Fail 21: 137-155.

58. Biegus J, Zymlinski R, Sokolski M, Todd J, Cotter G, et al. (2019) Serial assessment of spot urine sodium predicts effectiveness of decongestion and outcome in patients with acute heart failure. Eur J Heart Fail. 21: 624-633.

59. Felker GM, O'Connor CM, Braunwald E, Heart failure clinical research network investigators (2009) Loop diuretics in acute decompensated heart failure: necessary? Evil? A necessary evil? Circ Heart Fail 2: 56-62. [Crossref]

60. Butler J, Forman DE, Abraham WT, Gottlieb SS, Loh E, et al. (2004) Relationship between heart failure treatment and development of worsening renal function among hospitalized patients. Am Heart J 147: 331-338. [Crossref]

61. Cooper HA, Dries DL, Davis CE, Shen YL, Domanski MJ (1999) Diuretics and risk of arrhythmic death in patients with left ventricular dysfunction. Circulation 100: 13111315. [Crossref]

62. Philbin EF, Cotto M, Rocco TA Jr, Jenkins PL (1997) Association between diuretic use, clinical response, and death in acute heart failure. Am J Cardiol 80: 519-522. [Crossref]

63. Forman DE, Butler J, Wang Y, Abraham WT, O'Connor CM, et al. (2004) Incidence, predictors at admission, and impact of worsening renal function among patients hospitalized with heart failure. J Am Coll Cardiol 43: 61-67.

64. Eshaghian S, Horwich TB, Fonarow GC (2006) Relation of loop diuretic dose to mortality in advanced heart failure. Am J Cardiol 97: 1759-1764. [Crossref]

65. Neuberg GW, Miller AB, O'Connor CM, Belkin RN, Carson PE, et al. (2002) Diuretic resistance predicts mortality in patients with advanced heart failure. Am Heart $J 144$ : 31-38. [Crossref]
66. Mielniczuk LM, Tsang SW, Desai AS, Nohria A, Lewis EF, et al. (2008) The association between high-dose diuretics and clinical stability in ambulatory chronic heart failure patients. J Card Fail 14: 388-393.

67. Salvador DR, Rey NR, Ramos GC, Punzalan FE (2005) Continuous infusion versus bolus injection of loop diuretics in congestive heart failure. Cochrane Database Syst Rev CD003178. [Crossref]

68. Aaser E, Gullestad L, Tollofsrud S, Lundberg J, Hall C, et al. (1997) Effect of bolus injection versus continuous infusion of furosemide on diuresis and neurohormonal activation in patients with severe congestive heart failure. Scandinavian J Clin Lab Invest 57: 361-367.

69. Pivac N, Rumboldt Z, SardeliA S, Bagatin J, PoliA S, et al. (1998) Diuretic effects of furosemide infusion versus bolus injection in congestive heart failure. Int $J$ Clin Pharmacol Res 18: 121-128. [Crossref]

70. Dormans TPJ, Vanmeyel JJM, Gerlag PGG, Tan Y, Russel FGM, et al. (1996) Diuretic efficacy of high dose furosemide in severe heart failure: bolus injection versus continuous infusion. J Am Coll Cardiol. 28: 376-382.

71. Kramer WG, Smith WB, Ferguson J, Serpas T, GrantAG, et al. (1996) Pharmacodynamics of torsemide administered as an intravenous injection and as a continuous infusion to patients with congestive heart failure. J Clin Pharmacol 36: 265-270.

72. Lahav M, Regev A, Raanani P, Theodor E (1992) Intermittent administration of furosemide vs continuous infusion preceded by a loading dose for congestive-heartfailure. Chest 102: 725-731.

73. Schuller D, Lynch JP, Fine D (1997) Protocol-guided diuretic management: comparison of furosemide by continuous infusion and intermittent bolus. Crit Care Med 25: 19691975. [Crossref]

74. Licata G, Di Pasquale P, Parrinello G, Cardinale A, Scandurra A, et al. (2003) Effects of high-dose furosemide and small-volume hypertonic saline solution infusion in comparison with a high dose of furosemide as bolus in refractory congestive heart failure: long-term effects. Am Heart $J$ 145: 459-466. [Crossref]

75. Palazzuoli A, Pellegrini M, Ruocco G, Martini G, Franci B, et al. (2014) Continuous versus bolus intermittent loop diuretic infusion in acutely decompensated heart failure: a prospective randomized trial. Crit Care 18: R134.

76. Ng KT, Yap JLL (2018) Continuous infusion vs. intermittent bolus injection of furosemide in acute decompensated heart failure: systematic review and meta-analysis of randomised controlled trials. Anaesthesia 73: 238-247. [Crossref]

77. Kuriyama A, Urushidani S (2019) Continuous versus intermittent administration of furosemide in acute decompensated heart failure: a systematic review and metaanalysis. Heart Fail Rev 24: 31-39. [Crossref]

Copyright: $\odot 2019$ Bonasia V. This is an open-access article distributed under the terms of the Creative Commons Attribution License, which permits unrestricted use, distribution, and reproduction in any medium, provided the original author and source are credited. 